\title{
Genetic structure of Mesoamerican populations of Big-leaf mahogany (Swietenia macrophylla) inferred from microsatellite analysis
}

\author{
RACHEL ROTH NOVICK, ${ }^{*}$ II CHRISTOPHER W. DICK, † MARISTERRA R. LEMES, \\ CARLOS NAVARRO,§ADALGISA CACCONE* and ELDREDGE BERMINGHAM† \\ *Department of Ecology E Evolutionary Biology, Yale University, New Haven, CT 06511, USA, +Smithsonian Tropical Research \\ Institute, Box 2072 Balboa, Ancon, Panama, łLaboratório de Genética e Biologia Reprodutiva de Plantas, Instituto Nacional de \\ Pesquisas da Amazônia, C. P. 478, Manaus, AM, 69011-970, Brazil, §Tropical Agricultural Center for Research and Higher Education \\ (CATIE), Turrialba 7170, Costa Rica
}

\begin{abstract}
While microsatellites have been used to examine genetic structure in local populations of Neotropical trees, genetic studies based on such high-resolution markers have not been carried out for Mesoamerica as a whole. Here we assess the genetic structure of the Mesoamerican mahogany Swietenia macrophylla King (big-leaf mahogany), a Neotropical tree species recently listed as endangered in CITES which is commercially extinct through much of its native range. We used seven variable microsatellite loci to assess genetic diversity and population structure in eight naturally established mahogany populations from six Mesoamerican countries. Measures of genetic differentiation $\left(F_{\mathrm{ST}}\right.$ and $\left.R_{\mathrm{ST}}\right)$ indicated significant differences between most populations. Unrooted dendrograms based on genetic distances between populations provide evidence of strong phylogeographic structure in Mesoamerican mahogany. The two populations on the Pacific coasts of Costa Rica and Panama were genetically distant from all the others, and from one another. The remaining populations formed two clusters, one comprised of the northern populations of Mexico, Belize and Guatemala and the other containing the southern Atlantic populations of Nicaragua and Costa Rica. Significant correlation was found between geographical distance and all pairwise measures of genetic divergence, suggesting the importance of regional biogeography and isolation by distance in Mesoamerican mahogany. The results of this study demonstrate greater phylogeographic structure than has been found across Amazon basin S. macrophylla. Our findings suggest a relatively complex Mesoamerican biogeographic history and lead to the prediction that other Central American trees will show similar patterns of regional differentiation.

Keywords: mahogany, Meliaceae, Mesoamerica, microsatellites, population genetics, Swietenia macrophylla
\end{abstract}

Received 25 March 2003; revision received 10 July 2003; accepted 10 July 2003

\section{Introduction}

For rare Neotropical trees, the current rate of deforestation in Mesoamerica is sufficiently high to endanger their continued existence through habitat loss and the potential lack of gene flow as a result of forest fragmentation.

Correspondence: Rachel Roth Novick. IIPresent address: Yale University, Department of Ecology \& Evolutionary Biology, OML 165 Prospect Street, New Haven, CT 06511, USA. E-mail: rachel.novick@yale.edu
The approach to extinction, or at the least the severe loss of genetic diversity, may be further accelerated for tree species that are not only rare but have a high economic value, leading to their harvest in otherwise undisturbed forest. With an average density of one commercial-sized tree per hectare and the highest priced wood in the Neotropics, conservation of Swietenia macrophylla (big-leaf mahogany) is a subject of increasing concern for governments and conservationists alike. In order to address this concern and provide data on regional patterns of population genetic structure in Neotropical trees, we have 
undertaken a microsatellite-based analysis of S. macrophylla across its Mesoamerican range.

Although the species' natural range stretches from southern Mexico to the southern Amazon basin in Brazil, deforestation has destroyed a large percentage of the mahogany-containing forests (Gillies et al. 1999). Conserving genetic diversity is additionally important in this case because of evidence that vertical growth, degree of branching, and shoot borer resistance are heritable traits (Newton et al. 1999). The other two members of Swietenia, S. humilis on the Pacific coast of Central America and S. mahoganii in the Caribbean, both appear capable of hybridizing with $S$. macrophylla but their ranges are generally non-overlapping (Pennington 1981). Like Central American S. macrophylla, both S. humilis and S. mahoganii are now considered commercially extinct throughout most of their ranges.

Swietenia macrophylla is a monoecious canopy emergent tree. The small unisexual flowers are pollinated by generalist moths or small bees (Styles 1972), suggesting restricted pollen flow relative to tree species visited by specialist pollinators which have more extensive foraging ranges. A mating study of two Costa Rican mahogany populations also indicated very limited pollen flow, on the order of $200 \mathrm{~m}$ (Lowe et al. 2003). Most of the large, wind-dispersed winged seeds of mahogany fall near the maternal tree, and in a study of Bolivian S. macrophylla the median dispersal distance was 32-36 m, with a maximum of about $80 \mathrm{~m}$ (Gullison et al. 1996). Seeds do not remain viable beyond one rainy season and seedlings do not survive long in the shade. It appears that Mesoamerican mahogany often regenerates in even-aged cohorts, suggesting that recruitment may depend on periodic catastrophic disturbances, specifically hurricanes and fires (Snook 1996). However, this conclusion is based on the assumption that plant size and ages are closely correlated, which is not true for many tropical trees (Chambers et al. 1998).

Given the intense conservation and economic interests, it is not surprising that mahogany has been the subject of more genetic studies than any other Neotropical tree. Helgason et al. (1996) studied populations of S. macrophylla from Belize and Costa Rica and found no variation in chloroplast DNA sequence. A microsatellite study of $S$. humilis in fragmented forest stands in Honduras also discovered little variation between populations, but high overall levels of heterozygosity and allelic diversity (White et al. 1999). Two of the first regional-scale population genetic investigations of Neotropical trees focused on S. macrophylla; one was a random amplified polymorphic DNA analysis of 19 Mesoamerican mahogany populations (Gillies et al. 1999), and the other a microsatellite-based study of seven populations spread across $2100 \mathrm{~km}$ of Amazonian lowland forest (Lemes 2000; Lemes et al. 2003). Both studies revealed considerable genetic variation within populations and moderate genetic differentiation among populations.
Our population sampling of S. macrophylla across its Mesoamerican range covers largely the same region investigated by Gillies et al. (1999), but we employed microsatellite markers developed for this species by Lemes et al. (2002). The acquisition of additional data based on co-dominant microsatellite markers provides a more detailed population genetic characterization of Mesoamerican mahogany, while laying the foundation for our forthcoming comparative analysis of S. macrophylla across its entire South and Mesoamerican range.

Given the relatively high levels of microsatellite variation observed in previous studies of S. macrophylla (Lemes 2000; Lemes et al. 2002; Lemes et al. 2003), we hypothesized that overall genetic diversity of Mesoamerican mahogany would be comparable to that of Amazonian mahogany. However, given Mesoamerica's elongate geography and greater natural fragmentation, we posited an increased influence of landscape heterogeneity on population subdivision in comparison to Amazonian mahogany. As the first microsatellite study of a Mesoamerican tree at this geographical scale, we anticipate that our results will provide a foundation for future comparative biogeographic studies of the region's flora. In addition, we hope that improved genetic characterization of Mesoamerican $S$. macrophylla will assist in the conservation of diversity in this endangered and highly valued species.

\section{Materials and methods}

Our study was based on seven variable microsatellite loci (Lemes et al. 2002) analysed in eight mahogany populations from six Mesoamerican countries. Sample sizes ranged from 16 to 55 individuals, with a mean sample of 36 trees per population. Our sampling was part of a 1995-97 survey of Central American mahogany conducted by CATIE (Tropical Agricultural Research and Higher Education Center, Turrialba, Costa Rica), and includes eight natural populations from Mexico (Nuevo Becal, $N=40$ ), Belize (Las Cuevas, $N=48$ ), Guatemala (Bethel, $N$ $=43$ and Tikal, $N=55$ ), Nicaragua (Mukuwas, $N=30$ ), Costa Rica (El Parque, $N=23$ and Santa Rosa, $N=16$ ) and Panama (Tonosí, $N=32$ ) (Fig. 1). The Bethel, Tikal (Guatemala) and Mukuwas (Nicaragua) sites were located in undisturbed forest while Nuevo Becal (Mexico), Las Cuevas (Belize), El Parque (Costa Rica), Santa Rosa (Costa Rica) and Tonosí (Panama) sites had been selectively logged. Adult mahogany trees (> $80 \mathrm{~cm}$ at breast height) were surveyed along linear transects until 65 trees were sampled or the forest block ended. Adult leaves or seeds were collected from individuals spaced at $\geq 100 \mathrm{~m}$ apart to reduce the probability of sampling from family clusters. We stored the adult leaves at $-20^{\circ} \mathrm{C}$ and subsequently germinated the seeds. Because the seedling tissue was more amenable to subsequent genetic analyses, we usually 


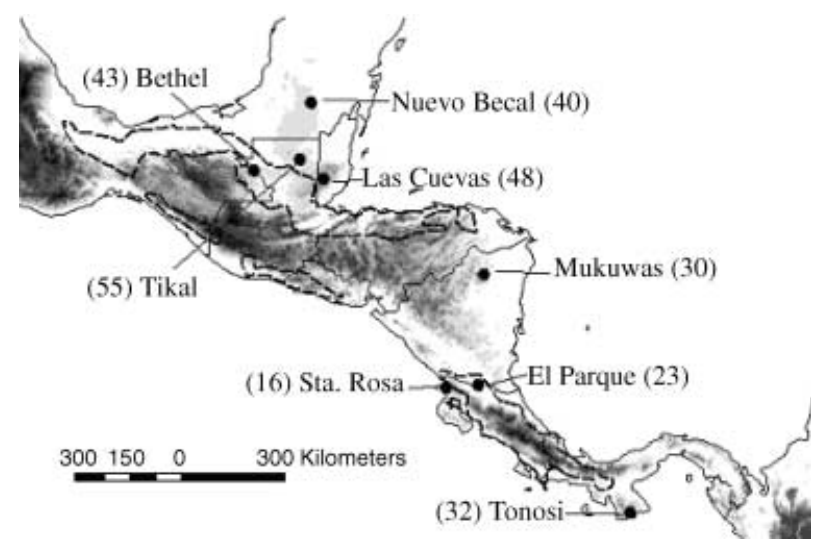

Fig. 1 Locations of Mesoamerican Swietenia macrophylla populations included in this study. Dashed lines enclose areas with $80 \%$ or greater likelihood of tropical forest persistence during the last ice age based on palaeoclimatic, geological and soil evidence (after Whitmore \& Prance 1987).

used tissue from a single seedling as a proxy for its mother tree.

Samples were ground in a FastPrep (Bio 101 Corporation) and DNA was extracted using the Qiagen Dneasy kit (Qiagen Corporation). DNA was quantified using a mass spectrometer and diluted $1: 100$ in distilled water to a concentration of approximately $10 \mu \mathrm{g} / \mathrm{mL}$ for polymerase chain reaction (PCR). Genetic diversity was assessed using seven of the nine polymorphic dinucleotide microsatellite loci developed and optimized for Swietenia macrophylla of the Brazilian Amazon (Lemes et al. 2002); the other two loci did not amplify consistently in Central American samples. PCR was performed in $10-\mu \mathrm{L}$ reactions containing $1 \times$ reaction buffer, $3.75 \mathrm{~mm} \mathrm{MgCl}_{2}, 6 \mu \mathrm{g}$ bovine serum albumin, $100 \mu \mathrm{M}$ of each dNTP, $2 \mu \mathrm{M}$ each of forward and reverse primer, $0.25 \mathrm{U}$ of Qiagen ${ }^{\circledR}$ Taq, $3 \mu \mathrm{g}$ template DNA and $\mathrm{H}_{2} \mathrm{O}$. The thermal conditions were: $95^{\circ} \mathrm{C}$ for $10 \mathrm{~min}, 30$ cycles of $95^{\circ} \mathrm{C}$ for $30 \mathrm{~s}, 56^{\circ} \mathrm{C}$ for $40 \mathrm{~s}$, and $72{ }^{\circ} \mathrm{C}$ for $1 \mathrm{~min}$, followed by a final elongation step of $15 \mathrm{~min}$ at $72{ }^{\circ} \mathrm{C}$.

PCR products were electrophoresed on $6 \%$ denaturing polyacrylamide gels using GeneScan-500 size standard (Applied Biosystems). Loci SM01, SM22, SM32 and SM51 were run on an MJ Research Base Station and analysed with the software CARTOGRAPHER (MJR). Loci SM31, SM40 and SM46 were run on an ABI 373 (Applied Biosystems) and analysed with GENESCAN and GENOTYPER (Applied Biosystems). The long final elongation ensured consistency in adenine addition across samples. Stutter was low and if allele sizes were unclear, samples were run again.

\section{Genetic analyses}

Allele frequencies and mean observed and unbiased expected heterozygosity (Nei 1987) were estimated using GENEPOP 3.2a (Raymond \& Rousset 1995). Hardy-Weinberg equilibrium and linkage disequilibrium for all locus pairs were tested by Fisher's exact test and $P$-values were determined by Monte Carlo Markov chain with 1000 iterations.

Levels of genetic differentiation among populations were assessed using the $F_{\mathrm{ST}}$ estimator $\theta$ (Weir \& Cockerham 1984) in FSTAT 2.9.3 (Goudet 1995), and $\rho$, Slatkin's (1995) estimator of $R_{\mathrm{ST}}$, in RSTCALC 2.2 (Goodman 1997). It is useful to present both parameters since each has its strengths and weaknesses. $F_{\mathrm{ST}}$ is deflated by a high mutation rate, which for microsatellites can be a significant factor, while $R_{\mathrm{ST}}$ is unaffected by mutation rate under a strict stepwise-mutation model. On the other hand, $R_{\mathrm{ST}}$ has a higher variance, particularly when sample sizes are small and vary in size (Ruzzante 1998). $F_{\mathrm{ST}}$ is more accurate for smaller, recently diverged populations while $R_{\mathrm{ST}}$ is more accurate for larger populations with longer divergence times (Balloux \& Lugon-Moulin 2002).

For pairwise estimations of these parameters, the exact $G$-test was used to determine significance of $\theta$-values (28 000 permutations) and $\rho$-values (1000 permutations) with Bonferroni corrections for multiple comparisons (Rice 1989). The average over loci $\left(R_{\mathrm{Stu}}\right)$ was used to estimate overall $R_{\mathrm{ST}}$ (Balloux \& Goudet 2002). The level of inbreeding was assessed using $F_{\text {IS }}$ (Weir \& Cockerham 1984). Significance of $\theta$ and $F_{\text {IS }}$ were tested using GENETIX 4.01 (Belkhir et al. 1996-98) with 1000 permutations.

Genetic distance was estimated using $(\delta \mu)^{2}$ based on the stepwise model of microsatellite mutation (Goldstein et al. 1995), and Nei's standard distance D (Nei 1987) using MicrosAt 1.5d (Minch et al. 1995-97). Simulations have shown that Nei's D has the highest probability of giving the correct topology when divergences are recent, whether using the infinite alleles or the stepwise-mutation model (Takezaki \& Nei 1996). Unlike some other measures of distance, differences in sample size across populations do not have a major effect on the sampling variance of Nei's D and $(\delta \mu)^{2}$ (Ruzzante 1998).

Populations were geo-referenced and pairwise geographical distances were calculated in ARCVIEW 3.2. Using the GENEPOP ISOLDE program, we tested the hypothesis that genetic distance between population pairs is dependent upon geographical distance. Correlation between geographical distance and $\theta$ and $\rho$ was assessed and significance was determined by the Mantel test (Mantel 1967) with 1000 permutations.

Cluster analysis was carried out using the UPGMA algorithm implemented in Phylip 3.573c (Felsenstein 1993) using both Nei's D and $\delta \mu^{2}$ pairwise distances. The significance of the best topology was estimated with 1000 bootstrap replicates and a consensus tree was constructed. Branch lengths were estimated using PAUP* $4.0 \mathrm{~b} 9$ (Swofford 2000). Comparisons with Amazonian data (Lemes 2000; Lemes et al. 2003) were performed using the two-tailed Wilcoxon test (Sokal \& Rohlf 1995). 
2888 R. R. NOVICK ET AL.

Table 1 Genetic variation in eight Mesoamerican mahogany populations for seven microsatellite loci combined

\begin{tabular}{lllllll}
\hline Population & $\mathrm{A}$ & $P_{\mathrm{A}}$ & $H_{\mathrm{O}}$ & $H_{\mathrm{E}}$ & $f$ & Disturbance history \\
\hline Nuevo Becal & $7.29(5-11)$ & 1 & $0.641(0.072)$ & $0.681(0.055)$ & 0.036 & Selectively logged \\
Las Cuevas & $8.86(5-13)$ & 2 & $0.511(0.092)$ & $0.593(0.094)$ & $0.135^{* * *}$ & Selectively logged \\
Bethel & $8.57(5-13)$ & 3 & $0.538(0.091)$ & $0.618(0.094)$ & $0.142^{* * *}$ & Undisturbed \\
Tikal & $7.86(5-10)$ & 0 & $0.578(0.079)$ & $0.619(0.076)$ & $0.067^{*}$ & Undisturbed \\
Mukuwas & $7.00(5-12)$ & 1 & $0.533(0.042)$ & $0.681(0.029)$ & $0.230^{* * *}$ & Undisturbed \\
El Parque & $6.43(4-10)$ & 0 & $0.470(0.049)$ & $0.626(0.052)$ & $0.247^{* * *}$ & Selectively logged \\
Santa Rosa & $7.71(4-11)$ & 3 & $0.672(0.047)$ & $0.799(0.042)$ & $0.174^{* * *}$ & Selectively logged \\
Tonosí & $6.86(5-9)$ & 4 & $0.527(0.040)$ & $0.639(0.052)$ & $0.175^{* * *}$ & Selectively logged \\
Total & 13 & 14 & 0.559 & 0.657 & 0.149 & \\
\hline
\end{tabular}

A, mean number of alleles (range in parentheses); $P_{\mathrm{A}^{\prime}}$ number of private alleles; $H_{\mathrm{O}}$, mean observed heterozygosity and $H_{\mathrm{E}^{\prime}}$ mean expected heterozygosity; (standard errors in parentheses); $f$, coefficient of inbreeding (estimator of $F_{\mathrm{IS}}$ ); ${ }^{* * *} P<0.1 \%,{ }^{*} P<5 \%$, and information about logging history.

Table 2 Estimated pairwise $F_{\mathrm{ST}}$ values above the diagonal and $R_{\mathrm{ST}}$ values below the diagonal for eight Mesoamerican mahogany populations

\begin{tabular}{|c|c|c|c|c|c|c|c|c|}
\hline & Nuevo Becal & Las Cuevas & Bethel & Tikal & Mukuwas & El Parque & Sta. Rosa & Tonosí \\
\hline Nuevo Becal & - & $0.046^{* * *}$ & $0.036^{* * *}$ & $0.057^{* * *}$ & $0.080^{* * *}$ & $0.086^{* * *}$ & $0.075^{* * *}$ & $0.210^{* * *}$ \\
\hline Las Cuevas & $0.013^{* *}$ & - & $0.020^{* * *}$ & $0.005^{*}$ & $0.108^{* * *}$ & $0.132^{* * *}$ & $0.091^{* * *}$ & $0.238^{* * *}$ \\
\hline Bethel & $0.049^{* * *}$ & $0.029^{* *}$ & - & $0.023^{* * *}$ & $0.112^{* * *}$ & $0.124^{* * *}$ & $0.069^{* * *}$ & $0.220^{* * *}$ \\
\hline Tikal & $0.038^{* * *}$ & 0.011 & $0.036^{* * *}$ & - & $0.099^{* * *}$ & $0.125^{* * *}$ & $0.087^{* * *}$ & $0.208^{* * *}$ \\
\hline Mukuwas & $0.080^{* * *}$ & $0.086^{* * *}$ & $0.100^{* * *}$ & $0.078^{* * *}$ & - & 0.015 & $0.070^{* * *}$ & $0.187^{* * *}$ \\
\hline El Parque & $0.113^{* * *}$ & $0.120^{* * *}$ & $0.121^{* * *}$ & $0.125^{* * *}$ & 0.010 & - & $0.096^{* * *}$ & $0.212^{* * *}$ \\
\hline Sta. Rosa & $0.160^{* * *}$ & $0.156^{* * *}$ & $0.157^{* * *}$ & $0.148^{* * *}$ & $0.076^{* *}$ & $0.080^{* *}$ & - & $0.167^{* * *}$ \\
\hline Tonosí & $0.259^{* * *}$ & $0.274^{* * *}$ & $0.277^{* * *}$ & $0.238^{* * *}$ & $0.310^{* * *}$ & $0.344^{* * *}$ & $0.272^{* * *}$ & - \\
\hline
\end{tabular}

${ }^{* * *} P<0.1 \%,{ }^{* *} P<1 \%,{ }^{*} P<5 \%$.

\section{Results}

We analysed 287 individuals representing eight populations of Mesoamerican mahogany, and observed a mean of 13.0 alleles per locus for seven microsatellite loci. All loci demonstrated independent inheritance, with no locus pairs showing significant linkage disequilibrium across populations. The Nuevo Becal population demonstrated overall linkage disequilibrium, with 26 out of 28 locus pairs having significant linkage $(P<$ $0.05)$. However, this pattern was restricted to this population. The mean number of alleles per locus across all populations for the seven microsatellites studied was 7.27 (Table 1). The highest and lowest mean number of alleles was observed for Las Cuevas (8.86) and El Parque (6.43), respectively. Expected heterozygosity ranged from 0.59 in Las Cuevas to 0.80 in Santa Rosa with a mean of 0.66 .

Tests for Hardy-Weinberg equilibrium demonstrated significant heterozygote deficits for each locus in about half the populations at the $P<0.05$ level. While all popula- tions except Nuevo Becal had a significant coefficient of inbreeding when all loci were combined, the number of loci with significant $F_{\text {IS }}$ values varied from one for Santa Rosa to five for Mukuwas.

The allele distributions were perfectly continuous for SM01. They were nearly continuous for all the others, skipping only one size class for SM22 and SM32 and two size classes for SM31 and SM40, suggesting that the stepwisemutation model is an appropriate model for mutation at these loci. The two measures of genetic differentiation $\theta$ and $\rho$ over all loci were each significantly different from zero $(P<0.001)$, with overall values of $\theta=0.109$ and $\rho=$ 0.177 . Pairwise calculations of $\theta$ and $\rho$ yielded significant values for 27 out of 28 population pairs for $\theta$ and 26 out of 28 pairs for $\rho$ (Table 2). Positive correlation $\left(R^{2}=0.624\right)$ was observed between geographical distance and genetic differentiation: $\theta(P=0.005)$ and $\rho(P=0.000)$. These correlations remained significant when Tonosí, the most distant population, was removed $(\theta, P=0.025 ; \rho, P=0.001)$. Figure 2 shows the correlation between $\rho$ and geographical distance. 


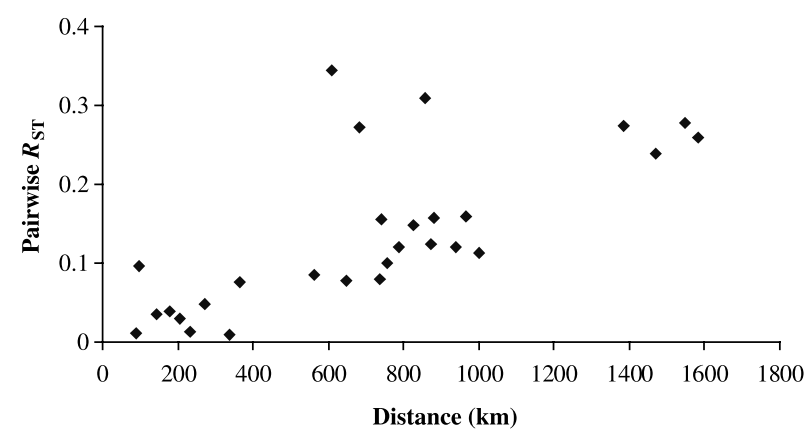

Fig. 2 Correlation between $R_{\mathrm{ST}}$ and geographical distance for eight populations of Mesoamerican mahogany.

Consensus trees constructed based on Nei's D and $\delta \mu^{2}$ distance measures (Fig. 3) resulted in trees with the same topology for more diverged populations but different topology for the populations of Mexico, Belize and Guatemala, those most closely related to each other. While $\delta \mu^{2}$ is the most reliable distance for older divergence, Nei's D is likely to be more accurate for the more closely related northern populations (Takezaki \& Nei 1996). Our unpublished results on chloroplast and mitochondrial DNA divergence between Central American mahogany populations indicates ages younger than the formation of the Panama land bridge $(\approx 3.1$ million years ago; Coates \& Obando 1996). The modest age of mahogany populations coupled with the species' long generation time suggests that microsatellites are appropriate for inferring relationships between populations. For example, Richard \& Thorpe (2001) demonstrated that microsatellite-based distance measures did not reach an asymptote at time scales of 3-6 million years in lizards and Goldstein et al. (1999) used microsatellites to construct a UPGMA tree of fox populations in the Channel Islands that accurately reflected historical relationships.

\section{Discussion \\ Levels of genetic variation within Mesoamerican populations}

While values for A (the average number of alleles observed over all loci and across all populations), and $H_{\mathrm{E}}$ (expected heterozygosity) fall within the range of other microsatellite studies of Neotropical trees (e.g. Chase et al. 1996; White \& Powell 1997), both values were significantly lower in this study $\left(\mathrm{A}=13.0, H_{\mathrm{E}}=0.66\right)$ than for Amazonian mahogany for the same loci $\left(\mathrm{A}=18.57, H_{\mathrm{E}}=0.79\right.$, Lemes 2000; Lemes et al. 2003) as determined by two-tailed Wilcoxon test $(P<0.05)$. While the Central American populations would be expected to contain only a subset of the diversity of the Brazilian populations if the species originated in South America, we lack fossil evidence establishing the geographical origin of Swietenia macrophylla. It is worth noting, however, that the northern distribution of all three species of Swietenia (Pennington 1981) favours a Mesoamerican origin for S. macrophylla.

Two additional hypotheses may account for the reduced allelic diversity of Mesoamerican mahogany populations. First, the long-term effective population size(s) of S. macrophylla in Mesoamerica may be considerably smaller than in Amazonia owing to differences in land area and suitable mahogany habitat, or to relative changes in habitat area as a result of historical climate change. We estimate that the area of mahogany habitat in South America may exceed that in Mesoamerica by a factor of four based on Pennington (1981) and Calvo (2000). The effects of climate change on the habitat area occupied by mahogany are more difficult to calculate. Climate change associated with the Pleistocene glaciations is thought to have restricted rainforest cover more severely in Mesoamerica than in South America (Whitmore \& Prance 1987), thus exaggerating current
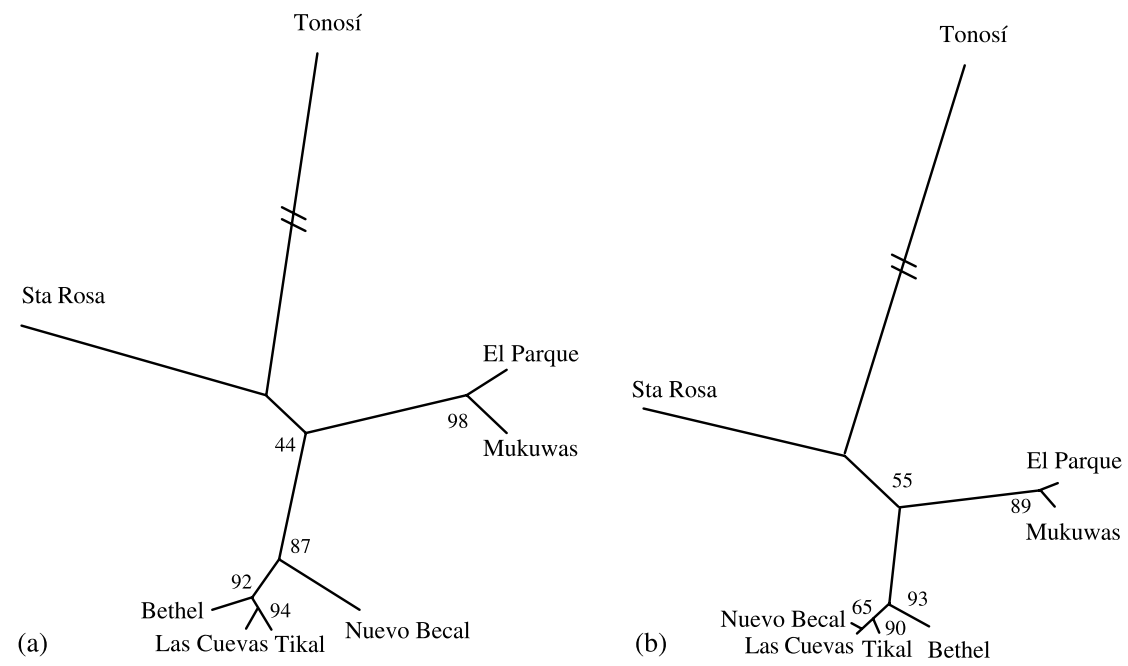

(c) 2003 Blackwell Publishing Ltd, Molecular Ecology, 12, 2885-2893
Fig. 3 UPGMA consensus trees for Mesoamerican mahogany populations constructed using (a) Nei's D and $(b)(\delta \mu)^{2}$ distance measures. Values indicate the percentage of 1000 bootstrap replicates supporting the node. Branch lengths are proportional to genetic distance except for Tonosí. 
regional differences in the effective population sizes of rainforest trees. However, S. macrophylla favours relatively dry seasonal forests, and thus mahogany populations might have expanded during the glacial periods. Even in this case it appears likely that the effective population of mahogany would have been greater in South America than Mesoamerica, given the hypothesis of Prado \& Gibbs (1993) indicating a significant expansion of dry forest in the southern Amazonian arc during the last glacial maximum. Under either habitat change scenario, it appears likely that the difference in effective population size of mahogany in South America and Mesoamerica would have been accentuated, resulting in loss of Mesoamerican diversity through genetic drift.

Second, the lower diversity of Mesoamerican mahogany may have resulted from recent reductions in population size caused by the extremely high rate of mahogany logging in the region, as well as the greater severity and duration of Mesoamerican deforestation as compared to the Amazon. Selective logging has been shown for other timber species to lead to an increase in self-fertilization (Murawski et al. 1994), and a loss of genetic diversity (Lee et al. 2002). However, three of the eight mahogany populations sampled here represent unlogged forests, and thus have not suffered the reductions in local tree density that can promote inbreeding. Moreover, it has been shown that highly isolated trees of $S$. humilis experience extensive long-distance gene flow by pollen (White et al. 2002). Given the additional fact that the three unlogged forests (Bethel, Tikal and Mukuwas) and the five selectively logged forests (Nuevo Becal, Las Cuevas, El Parque, Santa Rosa and Tonosí) have similar inbreeding coefficients and allelic diversities, it is unlikely that selective logging explains the lower levels of genetic diversity in Mesoamerican S. macrophylla.

Furthermore, we do not consider anthropogenic forest fragmentation to be a compelling explanation for the reduced genetic diversity. Given the long generation times of S. macrophylla relative to the time since deforestation, it is unlikely that sufficient time has passed for genetic drift to have caused a significant loss of alleles in most Mesoamerican mahogany populations. Although these factors argue against a causal role for logging or deforestation in the genetic erosion of Mesoamerican S. macrophylla, such an effect cannot be entirely discounted. To test such a hypothesis, it would be necessary to sample large numbers of adults in addition to the seedlings which comprise most of the samples considered here, and to compare genetic diversity in the two age classes.

The unusually high linkage disequilibrium found in almost all locus pairs in Nuevo Becal, the northernmost mahogany population in our study, suggests that the population was either recently established or has passed through a population bottleneck. There is a long history of mahogany trade in Mexico, where mahogany has been logged for the international market since the 17th century (Snook 1996). While evidence is lacking for decreased genetic variation among human-impacted populations of Swietenia spp. (Gillies et al. 1999; White et al. 1999), the record of logging in Mexico may be sufficiently long relative to the mahogany life cycle to register discernible population genetic change in harvested forests.

The generally high level of heterozygote deficiency across loci and populations prompts examination of factors that can lead to relatively high levels of homozygosity. The presence of a heterozygote deficiency at every locus, coupled with the fact that very few individuals failed to amplify (these may indicate null/null homozygotes), indicates that null alleles are unlikely to explain the heterozygote deficit. We also consider a Wahlund effect to be unlikely since trees within a population tend to flower simultaneously (Lowe et al. 2003). Thus, inbreeding would appear to represent the most likely explanation for the excess of homozygous alleles in the Mesoamerican populations of mahogany. This conclusion is corroborated by similar patterns observed in Amazonian S. macrophylla (Lemes 2000) in addition to a mating system analysis of the Brazilian trees in which $4.2 \%$ of seeds resulted from selffertilization or kin mating, showing that while inbreeding is low in this species, it is not negligible (Lemes 2000). Inbreeding may be increased by the small size and isolation of many of the populations utilized in our study. A microsatellite study of $S$. humilis on a local scale also demonstrated significant levels of inbreeding for each population, with $F_{\text {IS }}$ values ranging from 0.178 to 0.223 (White et al. 1999). Heterozygote deficits have been found in microsatellite studies of other tropical trees, e.g. Symphonia globulifera (Aldrich et al. 1998) and Melaleuca alternifolia (Rossetto et al. 1999). As the number of such studies increases, comparative analysis should reveal the relative occurrence of inbreeding in Neotropical trees, and its association with fragmented or selectively logged forest populations.

\section{Genetic differentiation among Mesoamerican populations}

This study demonstrates a moderate level of genetic structure among Mesoamerican mahogany populations. Overall $\theta(0.109)$ and $\rho$ (0.177) were similar to the values found in the Amazon populations for these loci $(\theta=0.091$; $\rho=0.144$; Lemes 2000; Lemes et al. 2003); while the Mesoamerican values were higher, the differences were not significant $(P>0.1$ for both, two-tailed Wilcoxon test). Since high mutation rates and reduced gene flow deflate $F_{\mathrm{ST}}$ values, $R_{\mathrm{ST}}$ tends to better reflect true differentiation when there is greater divergence between populations. Even though microsatellite mutation is likely to deviate somewhat from a strict stepwise-mutation model, $R_{\mathrm{ST}}$ is still expected to reflect population differentiation more 
accurately than $F_{\mathrm{ST}}$ as long as the mutation process involves some degree of memory. On the other hand, $F_{\mathrm{ST}}$ is less sensitive to bias resulting from low sample size and has a lower variance, making it more accurate for smaller, more recently diverged populations (Balloux \& LugonMoulin 2002). Both measures indicate moderate genetic differentiation of Mesoamerican populations on a par with that of Amazonian mahogany and the convergence of the two parameters indicates their biological relevance.

Only two microsatellite studies of Neotropical trees encompass the geographical scale of our study, and both demonstrate comparable levels of population subdivision. Population subdivision in Amazonian mahogany (Lemes 2000; Lemes et al. 2003) was discussed above, and Collevatti et al. (2001) reported moderate $\theta$ and high $\rho$-values for 10 populations of the animal-dispersed tree Caryocar brasiliense (Caryocaraceae) across a comparable geographical range in the Cerrado area of Brazil. More geographically localized microsatellite studies generally report lower values of genetic differentiation. With specific regard to Mesoamerican trees, wind-dispersed S. humilis in Honduras and gravity- and water-dispersed Carapa guianensis in Costa Rica, both members of the Meliaceae, had lower genetic differentiation with overall $\rho$-values of 0.032 (White et al. 1999) and 0.041 (Dayanandan et al. 1999), respectively, as did bat-dispersed Symphonia globulifera (Clusiaceae) in Costa Rica ( $\rho=0.056$, Aldrich et al. 1998). To the extent that the different microsatellite studies touched on here turn out to be representative, there is the suggestion of considerable evolutionary and ecological independence between geographically separated populations of Neotropical trees. Such independence has obvious theoretical and conservation implications.

Within Mesoamerica, the association between geography and population relatedness suggests a strong historical component to the contemporary population structure of mahogany (Fig. 3). The northern cluster provides evidence of a close relationship between the mahogany populations of Mexico, Belize and Guatemala, while the central Mesoamerican populations of El Parque (Costa Rica) and Mukuwas (Nicaragua) form an independent group, as do the distinctive Santa Rosa (Costa Rica) and Tonosí (Panama) populations. There is strong correspondence between the locations of the northern and central mahogany population clusters and the Mesoamerican glacial forest 'refugia' postulated by Whitmore \& Prance (1987). Based on a compilation of palaeoclimatic, geological and soil data, these authors argued that moist tropical forest persisted in two regions during the last Ice Age: one stretched from southern Mexico through Guatemala to northern Honduras, the other from southern Nicaragua through Costa Rica to northern Panama (Fig. 1).

The Pacific verdant populations of Tonosí and Santa Rosa fall outside the latitudinal or 'refugial' clusters formed by the six Caribbean slope mahogany populations. There are two factors potentially involved in the large genetic distance between Santa Rosa and Tonosí, and all other populations, and their lack of close genetic association with the other populations in the southern Mesoamerican 'refuge' posited by Whitmore \& Prance (1987). The first factor is linked to the geographical isolation of the populations on the Pacific side of the Talamanca mountain range, and in particular, to Tonosís location near the tip of Panama's Azuero Peninsula. Considering the large genetic distance, the split between the Santa Rosa and Tonosí populations and all others may have occurred early in the Mesoamerican expansion of mahogany, perhaps prior to the late Miocene development of the Talamanca mountain range. The second factor is introgression, as Santa Rosa is the only sampled population located within the range of S. humilis, raising the possibility that alleles have moved between these two mahogany species. However, comparative data on allele identities and genotypes for the two mahogany species are required to test this possibility. In addition, Lowe et al. (2003) suggest that environmental variation, such as differences in habitat moisture, may increase genetic differentiation, and Santa Rosa is in a drier area than the other populations. It is important to note that while microsatellites have been successfully used to reconstruct phylogenies between populations or closely related species, microsatellite-based distance measures are strongly affected by bottlenecks and fluctuations in population size (Richard \& Thorpe 2001) and therefore must be treated cautiously.

The strong isolation by distance pattern found in this study is consistent with other large-scale studies of tropical trees, for example Caryocar brasiliense in the Cerrado area of Brazil (Collevatti et al. 2001) and Euterpe edulis in the Brazilian Atlantic rainforest (Cardoso et al. 2000). Isolation by distance was observed for Amazonian S. macrophylla (Lemes et al. 2003), but the Mesoamerican populations also form natural groups based on geographical isolation, which raises the possibility that the pattern observed for Mesoamerican mahogany owes more to the geography of the region than distance per se. Although one of the two population pairs that produced insignificant pairwise $F_{\mathrm{ST}}$ and/or $R_{\mathrm{ST}}$ values are geographical nearest neighbours (Las Cuevas, Belize and Tikal, Guatemala), the other pair (El Parque, Costa Rica and Mukuwas, Nicaragua) are separated by $339 \mathrm{~km}$ (representing the eighth shortest geographical distance). Freshwater catfish in the genus Rhamdia show a similar geographical pattern and harbour virtually identical mitochondrial DNA (mtDNA) haplotypes among Caribbean slope populations of Costa Rica and Nicaragua, which are strongly differentiated from mtDNA haplotypes found to the north (Guatemala and Mexico) and on the Pacific slope of Panama (Perdices et al. 2002). The congruence between population differentiation 
and geography for organisms as different as mahogany and catfish suggests that historical biogeography has probably played a more important role in structuring mahogany populations at this scale in Mesoamerica than in Amazonia. If studied at a more local scale, other factors such as pollinator movement and seed dispersal would undoubtedly increase in importance relative to geography.

In recent years, microsatellites have made possible the first high-resolution genetic studies of Neotropical trees at large geographical scales. With this powerful tool, it is becoming increasingly possible to integrate our understanding of genetic diversity on scales ranging from individual trees to continental metapopulations. Future Mesoamerican studies of Neotropical trees will demonstrate whether the biogeographic patterns in allele distribution demonstrated for mahogany exist for other species. We anticipate that efforts to conserve mahogany will be facilitated by the knowledge that Mesoamerican S. macrophylla is comprised of genetically distinct regional populations.

\section{Acknowledgements}

Samples were graciously provided by the mahogany genebank established at CATIE and partly supported by funding from the European Commission, under framework III of DGXII, contract number TS3*-CT94 \pm 0316 . Funding was provided by the Yale Tropical Resources Institute, the Yale Institute for Biospheric Studies, the International Plant Genetics Resource Institute (LOA 00/ 063), STRI's molecular systematics and evolution program, and an anonymous donor and friend of the Yale School of Forestry and Environmental Studies. Thank you to Maribel Gonzalez, Jenny Acevedo, Yaxelis Mendoza, Elsie Rivera and Barbara Parsons for laboratory assistance and to Luciano Beheregaray, Saverio Vicario and Evgeniy Gladyshev for advice on analysis.

\section{References}

Aldrich PR, Hamrick JL, Chavarriaga P, Kochert G (1998) Microsatellite analysis of demographic genetic structure in fragmented populations of the tropical tree Symphonia globulifera. Molecular Ecology, 7, 933-944.

Balloux F, Goudet J (2002) Statistical properties of population differentiation estimators under stepwise mutation in a finite island model. Molecular Ecology, 11, 771-783.

Balloux F, Lugon-Moulin N (2002) The estimation of population differentiation with microsatellite markers. Molecular Ecology, 11, 155-165.

Belkhir K, Borsa P, Chikhi L, Goudet J, Bonhomme F (1996-98) Genetix 4.01: Windows ${ }^{\mathrm{TM}}$ Software for Population Genetics. University of Montpelier II, Laboratoire Genome de Populations, Montpelier, France.

Calvo J (2000) Evaluation of Mahogany (Swietenia macrophylla King) in Mesoamerica. PROARCA-CAPAS, Tropical Science Center, Costa Rica.

Cardoso SRS, Eloy NB, Provan J, Cardoso MA, Ferreira PCG (2000) Genetic differentiation of Euterpe edulis Mart. populations estimated by AFLP analysis. Molecular Ecology, 9, 17531760.
Chambers JQ, Higuchi N, Schimel JP (1998) Ancient trees in Amazonia. Nature, 391, 135-136.

Chase M, Moller C, Kesseli R, Bawa K (1996) Distant gene flow in tropical trees. Nature, 383, 398-399.

Coates AG, Obando JA (1996) The geologic evolution of the Central American isthmus. In: Evolution and Environment in Tropical America (ed. Coates AG), pp. 21-56. University of Chicago Press, Chicago.

Collevatti RG, Grattapaglia D, Hay JD (2001) Population genetic structure of the endangered tropical tree species Caryocar brasiliense, based on variability at microsatellite loci. Molecular Ecology, 10, 349-356.

Dayanandan S, Dole J, Bawa K, Kesseli R (1999) Population structure delineated with microsatellite markers in fragmented populations of a tropical tree, Carapa guianensis (Meliaceae). Molecular Ecology, 8, 1585-1592.

Felsenstein J (1993) PHYLIP: phylogenetic inference package, Version 3.573c. University of Washington, Seattle, WA.

Gillies ACM, Navarro C, Lowe AJ, Newton AC, Hernandez M, Wilson J, Cornelius JP (1999) Genetic diversity in Mesoamerican populations of mahogany (Swietenia macrophylla), assessed using RAPDS. Heredity, 83, 722-732.

Goldstein DB, Ruiz-Linares A, Feldman M, Cavalli-Sforza LL (1995) Genetic absolute dating based on microsatellites and origin of modern humans. Proceedings of the National Academy of Sciences of the USA, 92, 6720-6727.

Goldstein DB, Roemer GW, Smith DA, Reich DE, Bergman A, Wayne RK (1999) The use of microsatellite variation to infer population structure and demographic history in a natural model system. Genetics, 151, 797-801.

Goodman SJ (1997) RST CALC: a collection of computer programs for calculating unbiased estimates of genetic differentiation and determining their significance for microsatellite data. Molecular Ecology, 6, 881-885.

Goudet J (1995) FSTAT (Version 1.2): a Computer Program to Calculate F-Statistics. Journal of Heredity, 86, 485-486.

Gullison RE, Panfil SN, Strouse JJ, Hubbell SP (1996) Ecology and management of mahogany (Swietenia macrophylla King) in the Chimanes Forest, Beni, Bolivia. Botanical Journal of the Linnean Society, 122, 9-34.

Helgason T, Russell SJ, Monro AK, Vogel JC (1996) What is mahogany? The importance of a taxonomic framework for conservation. Botanical Journal of the Linnean Society, 122, 4759 .

Lee CT, Wickneswari R, Mahani MC, Zakri AH (2002) Effect of selective logging on the genetic diversity of Scaphium macropodum. Biological Conservation, 104, 107-118.

Lemes MR (2000) Population genetic structure and mating system of Swietenia macrophylla King (Meliaceae) in the Brazilian Amazon: implications for conservation. PhD Thesis, University of Stirling, UK.

Lemes MR, Brondani RPV, Grattapaglia D (2002) Multiplexed systems of microsatellite markers for genetic analysis of mahogany, Swietenia macrophylla King (Meliaceae), a threatened Neotropical timber species. Journal of Heredity, 93, 287-291.

Lemes MR, Gribel R, Proctor J, Grattapaglia D (2003) Population genetic structure of mahogany (Swietenia macrophylla king, meliaceae) across the Brazilian Amaton, based on variation at microsatellite loci: implications for conservation. Molecular Ecology, 12, in press.

Lowe AJ, Jourde B, Breyne P, Colpaert N, Navarro C, Wilson J, Cavers S (2003) Fine-scale genetic structure and gene flow 
within Costa Rican populations of mahogany (Swietenia macrophylla). Heredity, 90, 268-275.

Mantel N (1967) The detection of disease clustering and a generalized regression approach. Cancer Research, 27, 209-220.

Minch E, Ruiz-Linares A, Goldstein D, Feldman M, Cavalli-Sforza L (1995-97) MICROSAT (Version 1.5d): a computer program for calculating various statistics on microsatellite allele data. Stanford University, Stanford, CA.

Murawski DA, Gunatilleke IAUN, Bawa KS (1994) The effects of selective logging on inbreeding in Shorea megisptophilla (Dipterocarpaceae) from Sri Lanka. Conservation Biology, 8, 9971002.

Nei M (1987) Molecular Evolutionary Genetics. Columbia University Press, New York.

Newton AC, Watt AD, Lopez F et al. (1999) Genetic variation in host susceptibility to attack by the mahogany shoot borer, Hypsipyla grandella (Zeller). Agricultural and Forest Entomology, 1, 11-18.

Pennington TD (1981) Meliaceae. Flora Neotropica Monograph 28. [Swietenioideae by BT Styles.] New York Botanical Garden, New York.

Perdices A, Bermingham E, Montilla A, Doadrio I (2002) Evolutionary history of the genus Rhamdia (Teleostei: Pimelodidae) in Central America. Molecular Phylogenetics and Evolution, 25, 172 189.

Prado DE, Gibbs PE (1993) Patterns of species distributions in the dry seasonal forests of South America. Annals of the Missouri Botanical Garden, 80, 902-927.

Raymond M, Rousset F (1995) GENEPOP (Version 3.2a): population genetics software for exact tests and ecumenicism. Journal of Heredity, 86, 248-249.

Rice WR (1989) Analyzing tables of statistical tests. Evolution, 43, 223-225.

Richard M, Thorpe RS (2001) Can microsatellites be used to infer phylogenies? Evidence from population affinities of the Western Canary Island lizard (Gallotia galloti). Molecular Phylogenetics and Evolution, 20, 351-360.

Rossetto M, Slade RW, Baverstock PR, Henry RJ, Lee LS (1999) Microsatellite variation and assessment of genetic structure in tea tree (Melaleuca alternifolia - Myrtaceae). Molecular Ecology, 8, 633-643.

Ruzzante DE (1998) A comparison of several measures of genetic distance and population structure with microsatellite data: bias and sampling variance. Canadian Journal of Fisheries and Aquatic Sciences, 55, 1-14.

Slatkin M (1995) A measure of population subdivision based on microsatellite allele frequencies. Genetics, 139, 457-462.

Snook LK (1996) Catastrophic disturbance, logging and the ecology of mahogany (Swietenia macrophylla King): grounds for listing a major tropical timber species in CITES. Botanical Journal of the Linnaean Society, 122, 35-46.

Sokal RR, Rohlf FJ (1995) Biometry, 3rd edn. WH Freeman, New York.

Styles BT (1972) The flower biology of the Meliaceae and its bearing on tree breeding. Silvae Genetica, 21, 175-182.

Swofford DL (2000) PAUP*: Phylogenetic Analysis Using Parsimony (*and Other Methods). Sinauer, Sunderland, MA.

Takezaki N, Nei M (1996) Genetic distances and reconstruction of phylogenetic trees from microsatellite DNA. Genetics, 144, 389 399.

Weir BS, Cockerham CC (1984) Estimating f-statistics for the analysis of population structure. Evolution, 38, 1358-1370.

White G, Powell W (1997) Isolation and characterization of microsatellite loci in Swietenia humilis (Meliaceae): an endangered tropical hardwood species. Molecular Ecology, 6, 851-860.

White G, Boshier DH, Powell W (1999) Genetic variation within a fragmented population of Swietenia humilis Zucc. Molecular Ecology, 8, 1899-1909.

White GM, Boshier DH, Powell W (2002) Increased pollen flow counteracts fragmentation in a tropical dry forest: an example from Swietenia humilis Zuccarini. Proceedings of the National Academy of Sciences, 99, 2038-2042.

Whitmore TC, Prance GT, eds. (1987) Biogeography and Quaternary History in Tropical America. Oxford Science Publications, Clarendon Press, Oxford.

This work was carried out in the laboratories of Adalgisa Caccone at Yale University and Eldredge Bermingham at the Smithsonian Tropical Research Institute (STRI). Maristerra Lemes is a researcher at the Brazilian Institute for Amazon Research (INPA) working on population genetics and conservation of tropical trees using molecular markers. Christopher Dick is a Tupper Postdoctoral Fellow at STRI, where he and E. Bermingham study the diversification history of Neotropical organisms. A. Caccone works on a variety of evolutionary genetics problems including island biogeography, population genetics of mosquitoes, and conservation genetics of giant tortoises. More information about research programs in the laboratories of A. Caccone and E. Bermingham can be found at http://www.yale.edu/yibs/ research/ecolab.html and http://nmg.si.edu/bermlab.htm. Carlos Navarro is a researcher at the Tropical Agricultural Research and Higher Education Center (CATIE) in Costa Rica. His major areas of interest are in the use of quantitative and molecular markers in conservation genetics of tropical trees. The research reported here represents part of Rachel Novick's MFS thesis at Yale University, where she is currently a PhD student. 